\title{
Information Content of Implicit Spot Prices Embedded in Single Stock Future Prices: Evidence from the Indian Market
}

\author{
Rajesh Pathak $^{a *}$, Thanos Verousis ${ }^{b}$ and Yogesh Chauhan ${ }^{c}$ \\ ${ }^{a, c}$ IBS-Hyderabad, ICFAI Foundation for HE \\ $b$ School of Management, University of Bath
}

\begin{abstract}
We examine the informational role of implicit spot market prices embedded in single stock futures (SSF) prices, in predicting the equilibrium prices of the underlying assets. Implied stock prices are computed using cost-of-carry model and pricing errors are examined for their characteristics and information content about future movement in spot prices. Besides, the returns of portfolios based on ranking of such pricing errors, are investigated and their consistency is verified by controlling for idiosyncratic factors such as firm's liquidity and size. The time series investigation of the information content in price discrepancy is performed using Carhart (1997) four factors model, to examine if pricing error is a priced risk factor. We find pricing errors exhibiting seasonality. The returns of the portfolios based on ranking of pricing errors, are significant and increase with portfolio ranks. Our results reveal that implied prices contain better information about equilibrium stock prices than that of observed stock prices. The results of time series investigation of the information content in pricing errors indicates a significant alpha implying that large pricing errors produce high returns consistently. We conclude that implied spot prices from SSFs market are useful for traders to profit in the spot market.
\end{abstract}

Keywords: Derivatives, Single-Stock-Futures, Cost-of-carry, Pricing-Error, Informed Trading JEL Classification: G120, G130

\section{Introduction}

\footnotetext{
${ }^{*}$ Correspondence to: Thanos Verousis, School of Management, University of Bath, e-mail: t.verousis@bath.ac.uk.
} 
In complete markets with no transactions cost and perfect information, the cost of carry model forecasts futures market's prices precisely. Not surprisingly, in the real world, the assumptions of complete market do not hold true. Therefore, futures market's prices often deviate from the cost of carry model estimates. Though arbitrageurs serve to narrow such inter-market price discrepancies, largely through simultaneous submission of stock and futures trades (Cummings and Frino, 2011), yet the disruption of cost of carry relationship is reported frequently in literature (Vipul, 2005 \& 2008; Bialkowski and Jakubowski, 2012). The informed trading in futures market, due to the inherent rewards of trading derivatives (such as higher financial leverage, lower transaction cost, and allowance of a bearish position), is one of important reasons accredited in existing studies for such pricing errors. Consequently, the price changes in futures market lead the price changes in spot market (Chan et al., 1993; Shastri et. al., 2008; Theissen, 2012).

Exiting literature on the informational role of derivatives market largely examines options across time and space ( Chakravarty et al., 2004; Chen et al., 2005; Sarwar, 2005; Holowczak et al. 2007; Ni et al., 2008); and report conflicting results. For instance, Ni et al. (2008) study whether options volume is informative about future volatility of the underlying assets employing unique dataset of stock options trade provided by CBOE over the period of 1990 to 2001. They report significant positive relationship between options non market maker demand for volatility and subsequent realized volatility. Similarly, Chen et al. (2005) study the lead lag relationship between spot returns and trading value ratio. Classifying the sample based on factors such as options moneyness, market cycle, and liquidity, they show the options market leading in information impounding. Sarwar (2005) studies the relationship between expected future volatility of S\&P 500 Index and aggregate options volume. He reports an overall strong feedback relationship between the options volume and expected future volatility, with more pronounced results for at-the-money (ATM) and out-of-the money (OTM) options. Conversely, Holowczak, Simman and Wu (2007) study the price discovery in US stock and stock options market using portfolio approach and report low information share of options market.

Despite the voluminous literature on price discovery function of equity derivatives, studies on futures markets are few and very rare for Single Stock Futures (SSFs) in particular (Kumar and Tse, 2009; Brailsford and Cusack, 1997). We, in this study, empirically examine the information content in the pricing error of SSFs traded on National Stock Exchange (NSE), 
India; one of the leading exchanges worldwide in terms of trading number of stock futures. We examine the informativeness of pricing error using portfolio approach where portfolios are formed based on the relative deviation of spot prices from cost of carry-implied spot prices. We consider that if the market of SSFs is the venue where informed traders place their trade, then the futures market assessment of equilibrium stock values i.e. implied prices, would differ from observed spot market prices. Since the spot and derivatives, markets are linked through arbitrage relationship, the relative price differences of implied stock prices from observed stock prices could reveal information about future stock prices. To the best our knowledge, this is the first study that measures the information content of Single Stock Futures (SSFs) prices in predicting future stock returns.

We investigate this issue in an emerging economy India, due to the popularity of SSFs in Indian market (Figure 1) compared to other developed economies ${ }^{1}$. One plausible reason of SSFs being popular in the Indian market is the resemblance of futures contracts with Badla ${ }^{2}$ trades (Vipul, 2005). Nevertheless, the simple linear payoff structure of futures contracts, compared to that of options, might also have contributed in the preference of trading SSFs in Indian market that witness lower financial literacy. ${ }^{3}$

*** Insert Figure 1 around here ***

We begin our investigation by analysing the time series behaviour of pricing error followed by examination of information content in the pricing error in three alternative ways. First, we form daily portfolios of sample stocks based on daily ranking of pricing errors and compare the average portfolio returns. We find that the lowest (highest) ranked portfolios earning lowest (highest) returns indicating information content in pricing error about the future price movement. The results are tested for robustness using non-parametric chi-square $\left(\chi^{2}\right)$ test on

\footnotetext{
${ }^{1}$ It is noteworthy that in the years 2009 and 2010 the National Stock Exchange (NSE), India stood second to New York Stock Exchange (NYSE) - London International Financial Futures Exchange (LIFFE) in terms of the number of SSFs contracts traded. NSE in the years 2009 and 2010 traded 175.67 million and 161.05 million SSFs contracts compared to NYSE-LIFFE which traded 291.27 million and 179.03 million SSFs contracts. Source: http://www.nseindia.com/content/us/ismr_full2011.pdf

${ }^{2}$ Badla trading was a form of leveraged trading that involved buying stocks from borrowed money at a interest rate determined by demand of the particular stock and where stock exchange acted as an intermediary. Here, the broker was supposed to maintain mark to market margin.

${ }^{3}$ As per the Financial Literacy Report presented in Organisation for Economic Co-operation and Development (OECD)/World Bank/Reserve Bank of India Conference on Financial Education-2013, India scored 60 points to become second least financially literate country. New-Zealand tops the list with a score of 74 .
} 
rank-return distribution matrix. We find consistent result in terms of rank return distribution being significantly different from the random distribution.

Second, we repeat the above analysis after classifying sample stocks based on its liquidity and size. Liquidity and firm size are referred as important factors that affect trading venue preference of informed traders. Optimal trading strategy of an informed trader is to trade where uninformed trading is highest (Turkington and Walsh, 2000). It implies that informed trading should occur more in high liquid stocks. On the other hand, larger and older firms are expected to have less private information. Consequently, a large size firm should witness lesser informed trading than that of small size firms. We observe that the average of absolute pricing error is higher for liquid stocks however, we find contradicting results for firm size. Portfolio returns are consistent only for liquid stocks suggesting occurrence of informed trading.

Third, we perform the time series investigation of the information content in pricing errors using Carhart (1997) four factors model. We find a significant alpha $(\alpha)$ which reveals that pricing error is an important factor in explaining future stock returns. We also report the highest pricing error quintile stocks outperforming the least pricing error quintile stocks, on average, by $0.057 \%$ per day. The coefficients of other factors are consistent with literature in their sign and magnitude. Based on our investigations, we conclude that the implicit stock prices embedded in SSFs prices are informative about the future movement of stock prices in the spot market.

The rest of this paper is organized as follows. The next section outlines the methodology and data employed for this study. The subsequent section discusses the empirical results. The final section concludes the paper.

\section{Data and Methodology}




\subsection{Data}

We extract the closing prices of stock and stock future trades from the daily bhavcopy provided by NSE, India for the period January, 2004-December, 2011. We clean the data for missing observations and drop expiry week data to avoid the effect of squaring off activities near expiry term and other expiry effects. ${ }^{4}$ We have a final sample of 265 stocks trading in futures segment of NSE with 1490 days. In our sample, the number of days for which futures traded varied from stock to stock. Only 36 stocks were trading on the first observation date and additional stocks entered into the sample as futures trading expanded with time. Our final sample consists of 205629 daily observations. The risk free rate of interest is measured by the yield on 91 day Treasury Bills collected from the website of Reserve Bank of India (RBI), the Indian central bank. The data for dividends, daily market capitalization, number of shares traded and number of outstanding shares are collected from Prowess database provided by Centre for Monitoring Indian Economy (CMIE). The daily data for market, size, value and momentum factor premiums, to conduct the time series analysis of portfolio returns, is collected from the Indian market data library of Agrawalla, Jacob and Varma. ${ }^{5}$

\subsection{Methodology}

The Cost-of-carry $(\mathrm{CoC})^{6}$ model of futures pricing is based on the concept of arbitrage. The carrying charges are reflected by incorporating two costs i.e. the dividend yield $(d)$ if the stock is dividend paying and the financing charges $(r)^{7}$. The financial charges are presumed to be non-stochastic. If we revert the $\mathrm{CoC}$ equation for spot price $\left(\mathrm{S}_{\mathrm{t}}\right)$, it gives us the futures market's assessment of equilibrium spot market price of the stock i.e. implied stock price $\left(\mathrm{S}_{\mathrm{t}}{ }^{*}\right)$. The literary evidence of implied stock prices differing frequently from observed prices (Vipul, 2005 \& 2008; Wang, 2011) is difficult to accept from theoretical standpoint, as any such price discrepancy should disappear with no delay due to actions by arbitragers.

\footnotetext{
${ }^{4}$ We lose very insignificant amount of data in this process (less than $0.05 \%$ of observations).

${ }^{5}$ They compute factors for Indian market since 1995 using data from CMIE prowess database. More details about the database is available in Agrawalla, Jacob and Varma (2013).

${ }^{6}$ Cost of Carry $(\mathrm{CoC})$ Model: $\mathrm{F}_{\mathrm{t}}=\mathrm{S}_{\mathrm{t}} \mathrm{e}^{(\mathrm{r}-\mathrm{d})(\mathrm{T}-\mathrm{t})}$ or $\mathrm{S}_{\mathrm{t}}{ }^{*}=\mathrm{F}_{\mathrm{t}} \mathrm{e}^{-(\mathrm{r}-\mathrm{d})(\mathrm{T}-\mathrm{t})}$ where $\mathrm{S}_{\mathrm{t}}{ }^{*}$ is implicit stock price. Other two important models of futures pricing are the continuous time models by Ramaswamy and Sundaresan (1985) and Hemler and Longstaff (1991). A comparison of these three models in terms of their performance in explaining the futures prices by Brailsford and Cusack, (1997) indicates that none of them can be preferred over one another. We use CoC model for our study due to its simplicity.

${ }^{7}$ Dividend yields are adjusted due to the fact that unlike stock holders the investors long in futures contract are not entitled to receive the dividend paid on the underlying stock. Financing charges reflect the opportunity cost/borrowing charges of carrying the position in future based on whether the money invested is own money or is borrowed.
} 
However, there are arguments justifying the contrary. For instance, the financing charge $r$ in the cost-of-carry model is usually measured by risk-free rate of interest offered on treasury bills issued by the government. However, investors may demand extra premium over and above risk free rate due to the various risks they are exposed to by holding an equity-linked assets (such as liquidity premium to hold an illiquid stock). Besides, the informed trading in futures market may also result in implied spot prices deviating from observed spot prices revealing better information contained in futures prices about equilibrium stock prices.

The pricing error $\left(\Delta_{\mathrm{i}, \mathrm{t}}\right)$ for each of 265 stocks is computed for each observation date in the following way where $\mathrm{S}_{\mathrm{i}, \mathrm{t}}{ }^{*}$ is implied price of stock $\mathrm{i}$ on day $\mathrm{t}$ computed by reverting CoC equation for spot price, and $S_{i, t}$ is observed stock price of stock $i$ on day $t$ in the spot market.

$$
\Delta_{\mathrm{i}, \mathrm{t}}=\left(\mathrm{S}_{\mathrm{i}, \mathrm{t}}{ }^{*}-\mathrm{S}_{\mathrm{i}, \mathrm{t}}\right) / \mathrm{S}_{\mathrm{i}, \mathrm{t}}
$$

We find that the absolute mean pricing error for majority of stocks is less than $1 \%$ and the pricing error takes negative values more frequently. Only 74631 observations (36.29\%) in the pooled data of pricing error are positive values. If the observed pricing error relates to informed trading in stock futures market, the excessive negative observations indicate that the SSFs are traded primarily on negative information making the futures contracts undervalued.

We first examine the potential seasonality in the pricing error series. We believe that if pricing errors can predict stock returns then they may exhibit seasonality patterns similar to that of returns, which is well established in literature. We test if the cross sectional average of pricing error across days of the week and months of the year are same. We estimate following dummy variable regressions.

$$
\bar{\Delta}_{t}=\alpha+\sum_{l=1}^{4} \beta_{l} D_{l}+\varepsilon_{t}
$$

Here, $\bar{\Delta}_{t}$ is the cross sectional average of pricing errors [(Implied price-spot price)/spot price] on day t. $\mathrm{D}_{l}$ 's $(l=1$ to 4$)$ are dummies for weekdays i.e. $\mathrm{D}_{1}=$ Monday, ......., $\mathrm{D}_{4}=$ Thursday. Intercept $\alpha$ captures Friday effect. Dummies $D_{1}$ to $D_{4}$ takes value of 1 for the respective days that they represent and 0 otherwise. $\beta i$ 's are differential coefficients of different days viz a viz 
Friday and $\varepsilon_{t}$ is the error term. The significant $\beta$ 's would indicate if the average pricing errors on different days are different from that of Friday.

The following equation is estimated to examine the months of the year effect on the daily cross sectional average of pricing errors. Here $\gamma$ captures the base month (December) effect, $\lambda_{l}$ 's are differential coefficients of different months viz a viz December and $\mu_{\mathrm{t}}$ is the random error term.

$$
\bar{\Delta}_{t}=\gamma+\sum_{l=1}^{11} \lambda_{l} M_{l}+\mu_{t}
$$

Next, we examine if non-synchronous trading is the reason for observed pricing errors. Trading in both spot and futures segment on NSE stops at 3.30 PM every day. However, if the last trade in futures market occurs before the last trade in spot market then computed implied spot price $\left(\mathrm{S}_{\mathrm{t}}{ }^{*}\right)$ would only reveal the futures market assessment of within the day equilibrium price prior to the close of the market for the day. Let us assume that price of a stock $\mathrm{i}$ increases on a particular day. Then, the within day estimate of stock $\left(S_{i t}{ }^{*}\right)$ would be lower than the actual closing price $\left(S_{i t}\right)$. As a result, the pricing error would turn negative whereas returns on the stock on that day remain positive. This implies that a negative relationship of pricing errors with returns is indicative of non-simultaneity in the data. However, such within the day equilibrium prices may differ from the day end equilibrium prices in a purely random fashion too. We test for this phenomenon of non-simultaneity by estimating the following regression.

$$
R_{i, t}=\theta_{i}+\delta_{i} R_{m, t}+\pi_{i} \Delta_{i, t}+\psi_{i} \Delta_{i, t-1}+\varepsilon_{i, t}
$$

Here, $R_{i, t}$ represent the returns of stock $i$ on day $t, R_{m, t}$ is the market returns on day t measured by the equally weighted return of the sample stocks excluding stock i. We exclude stock i while computing market returns to avoid any endogeneity effect in the regression. Variables $\Delta_{\mathrm{i}, \mathrm{t}}$ and $\Delta_{\mathrm{i}, \mathrm{t}-1}$ are simultaneous and lag pricing error terms respectively for stock $\mathrm{i}$. $\varepsilon_{\mathrm{i}, \mathrm{t}}$ is the random error term. We expect the coefficient $\pi_{\mathrm{i}}$ to be negative for non-synchronous trading resulting in pricing error. However, even if non-synchronous trading turns out to be the major cause of pricing error, it may still contains latest information partially. We examine this possibility by including first lag of pricing error $\left(\Delta_{\mathrm{i}, \mathrm{t}-1}\right)$ in the above regression and expect the lag coefficient 
to be positive given negative coefficient of $\Delta_{\mathrm{i}, \mathrm{t}}$. The remaining tests are designed to examine the information content in implied prices.

For every stock, we compute pricing error $\left(\Delta_{\mathrm{i}, \mathrm{t}}\right)$ on each day and rank them from lowest to highest. Quintiles are formed on each day where portfolio 1 consists of $20 \%$ of the stocks with the lowest values of $\Delta_{\mathrm{i}, \mathrm{t}}$ and portfolio 5 consists the $20 \%$ of sample stocks with highest $\Delta_{\mathrm{i}, \mathrm{t}}$ values. The number of stocks in all portfolios on a given day is almost equal ${ }^{8}$ however; the number of stocks in a given portfolio across days of study varies from 7 to 47 due to inclusion of more stocks in futures segment over time. If the $\Delta_{\mathrm{i}, \mathrm{t}}$ is informative about future equilibrium price then the portfolio consisting stocks with lowest pricing error should have minimum returns and vice versa. We follow the trading rule as mentioned below for the portfolios returns analysis:

I. Compute $\Delta_{\mathrm{i}, \mathrm{t}}$ for each stock using futures market implied stock price on day t.

II. Buy stocks in the pth quintile $(\mathrm{p}=1,2, \ldots, 5)$ ranked by $\Delta_{\mathrm{i}, \mathrm{t}}$ at the close prices of day $\mathrm{t}$.

III. Sell the portfolio at close prices of day $\mathrm{t}+1$

It is notable that the above trading rules indicate ex-post nature of portfolio formation as it requires the investor to buy the portfolio at closing prices on day $t$. This is only possible for sophisticated investors who can receive and process the information simultaneously however, it is still useful to examine whether the portfolio returns differ based on the above trading rule. The average return of a portfolio over the period of study is computed following Manaster and Rendleman (1982). They mention that the changing number of stocks over time in a portfolio makes the portfolio returns hetroscedastic. The return of the portfolio with fewer stocks becomes more volatile than the returns of portfolio containing large number of stocks. They suggest computing the average portfolio returns by weighting the daily portfolio returns with the number of stocks in the portfolio on each day. We use the following expression to compute the average portfolio returns over the period of study.

$$
\overline{R_{p}}=\frac{\sum_{\mathrm{t}=1}^{\mathrm{n}}\left(\mathrm{W}_{\mathrm{t}}\right)\left(\mathrm{R}_{\mathrm{pt}}\right)}{\sum_{\mathrm{t}=1}^{\mathrm{n}} \mathrm{W}_{\mathrm{t}}}
$$

\footnotetext{
${ }^{8}$ When the total numbers of stocks are not in the multiple of 5 then the extra stocks are assigned following literature. If the extra stock/s is/are 1, 2, 3 or 4 that is/are assigned to portfolio/s $3 ; 2$ and 4; 2,3, and 4; and 1,2,4, and 5 respectively.
} 
Here, $\overline{R_{p}}$ is the time series average of returns on portfolio $\mathrm{p}, \mathrm{n}$ is number of days in the study, $\mathrm{W}_{\mathrm{t}}$ is the number of stocks included in portfolio $\mathrm{p}$ on day $\mathrm{t}$ and $\mathrm{R}_{\mathrm{pt}}$ is the return of portfolio $\mathrm{p}$ on day t. The computation of mean portfolio returns using above expression is similar to generalized least square regression estimates where variance of the residual term is supposed to vary with the reciprocal of W (Manaster and Rendleman, 1982). As the portfolios returns comparison test is ex-post in nature, we repeat the test by buying the portfolio at the closing price of the following day of portfolio formation and selling it on day $t+2$ which ensures that the information is available at the time of buying the portfolio. We call it the ex-ante test. We also perform robustness test to validate our results using non-parametric test. ${ }^{9}$

Next, we examine if the $\Delta$ s of the stocks and subsequent portfolio returns differ when factors such as liquidity and firm size are controlled for. Informed traders prefer to trade where liquidity traders trade (Turkington and Walsh, 2000) and a large size firm attracts less informed traders as it is expected to have less private information (Aslan et al., 2011). For liquidity, we use two alternative measures i.e. the daily turnover (number of traded shares/ total outstanding share) and the Amihud liquidity (Amihud, 2002) ${ }^{10}$. Firm size for the sample stocks is measured by $\log$ of daily market cap. We first form daily quintiles based on both measures of liquidity and firm size and then compute average pricing error for each quintile across study period. Next, we divide sample stocks in low, medium and high groups based on size and liquidity measures. Subsequently within each of these three groups, quintiles are formed based on $\Delta \mathrm{s}$ and portfolio returns are computed. These results help us to identify how these firm characteristic are related to informed trading.

We further argue that the deviation of observed spot price from implied price could simply be the result of additional compensation over risk free rate demanded by investors for holding risky equity position. Hence, the $\Delta$ becomes the measure of risk premium and so we expect the

\footnotetext{
${ }^{9}$ As a measure of robustness check we perform a related non parametric test to investigate if the portfolio formation based on ranking of pricing error is different from random portfolio selection. To carry out the test we rank the returns on the five portfolios on each day and expect that the return based ranking of the portfolio should not be related to the rankings of $\Delta$ 's if the formation of the portfolio is purely random. On the contrary, if $\Delta$ 's are informative then portfolios with highest ranks should consistently earn highest returns and vice-versa for lower ranked portfolios. We create a 5 by 5 matrix wherein each element indicates the number of days out of 1490 that a portfolio had the indicated return rank. We use chi-square test $\left(\chi^{2}\right)$ to determine if the frequency distribution in the matrix differs from the random distribution significantly. We use this procedure for both the ex-post and the ex-ante portfolio rank return distribution.

${ }^{10}$ Amihud Illiquidity measure captures the daily price response associated with one dollar of trading volume. In our study it is estimated by the ration of absolute daily return to daily dollar volume for each stock.
} 
firms with higher values of $\Delta$ earning higher returns. We estimate the following regression for each of the five portfolios that are formed based on ranking of $\Delta$ 's to assess if the pricing errors offer any additional information beyond that is given by Carhart (1997) factors.

$$
R_{\mathrm{p} t}=\alpha_{p}+\beta_{p} M K T_{t}+\gamma_{p} S M B_{t}+\delta_{p} H M L_{t}+\pi_{p} W M L_{t}+\varepsilon_{\mathrm{p}, t}
$$

Here, $\mathrm{R}_{\mathrm{pt}}$ is the excess return of portfolio $\mathrm{p}$ on day $\mathrm{t}, \mathrm{MKT}_{\mathrm{t}}, \mathrm{SMB}_{\mathrm{t}}, \mathrm{HML}_{\mathrm{t}}$ and $\mathrm{WML}_{\mathrm{t}}$ are Carhart (1997) factors ${ }^{11}$. MKT (Market Factor) represents excess return $\left(r_{m}-r_{f}\right)^{12}$ on broad market portfolio, SMB (Small minus Big) represents the difference between returns on the portfolio of large stocks and portfolio of small stocks whereas HML( High minus Low) represents the difference between the portfolio returns of high book to market stocks (value stocks) and the low book to market stocks (growth stocks). WML (winners minus losers) factor is computed by subtracting the average returns of highest performing firms from lowest performing firms. We expect the $\alpha_{\mathrm{p}}$ in the above regression to be significant for $\Delta$ 's to posses incremental information.

If $\Delta$ 's explain portfolio returns then the alphas across portfolios should increase with portfolio ranks and differ from each other. We test for this phenomenon using long-short portfolio strategy where an excess return on low $\Delta$ portfolio is subtracted from the excess return on high $\Delta$ portfolio. We estimate the following equation for this purpose.

$$
R_{\mathrm{p} t} *=\alpha_{p} *+\beta_{p} * M K T_{t}+\gamma_{p} * S M B_{t}+\delta_{p} * H M L_{t}+\pi_{p} * W M L_{t}+\varepsilon_{\mathrm{p}, t} *
$$

Where $\mathrm{R}_{\mathrm{pt}}{ }^{*}$ is the return of long short portfolio investment strategy on day t. We expect the $\alpha_{\mathrm{p}}{ }^{*}$ to be positive and significant if pricing error is a priced risk premium factor.

\footnotetext{
${ }^{11}$ Fama and French (1992) observed that two classes of stocks have tended to do better than the market as a whole as explained by CAPM (Capital Asset Pricing Model of Sharpe and Linter): They are (i) small caps and (ii) stocks with a high book-to-market ratio (BtM, customarily called value stocks, contrasted with growth stocks. They include two additional factors HML (high minus low) and SMB (small minus big) other than market factor in explaining returns. Carhart (1997) extended three factor model by adding factor for momentum (WML) computed by subtracting the average returns of highest performing firms from lowest performing firms.

${ }^{12}$ In the expression $\left(r_{m}-r_{f}\right) ; r_{m}$ represent return on the market portfolio whereas $r_{f}$ indicates the risk free rate.
} 


\section{Empirical Results}

Previous studies (Rogalski, 1984; Kiymaz and Berument, 2003) provide convincing evidence on the day of week effects in returns series. Most notably, the average return on Monday is negative. As pricing error constitute the potential rate of return if arbitrage is performed, we expect that pricing error should also exhibit the patterns of returns. Panel A and B of Table 1 reports day-of-week and month-of-the-year effects in pricing error series. The coefficient of Monday is negative and statistically significant at $1 \%$ level of significance. The pricing errors on other days are not found to be different from that of Friday. Pricing error in the month of December is significantly different from that of the months January, February, June, August and October at 5\% level of significance. However, the daily average pricing error is found to be negative across days of the week and months of the year. The results show a similar behaviour to that recognized for the stock returns series in literature. These results imply that if pricing error turns out to be informative then investors can choose specific days/months in a week/year to maximize their portfolio returns.

***insert Table 1 around here***

Table 2 contains the results of regression Equation (4) that test for the influence of nonsynchronous trading in explaining the price discrepancy of the two markets. We run regressions for each of the stocks (total 265 regressions) and the results thereof are summarized in Table 2. Results indicate an excessive inclination of $\pi_{\mathrm{j}}$ coefficients to be positive. Out of 265 stocks, $\pi_{\mathrm{j}}$ is found to be positive in 262 cases out of which 248 are found to be statistically significant at $5 \%$ level. Only three estimates of $\pi_{\mathrm{j}}$ are found to be negative out of which one is found to be significantly different from zero at $5 \%$ level of significance. This indicates that either implied prices contain better information compared to close spot price regarding future price movement, or it may just reveal the more recent information or both. The sign of pricing error lag coefficients show almost opposite trend where coefficients are found to be negative and significant frequently. In our sample of 265 stocks, 28 positive and 237 negative estimates are observed however, the number of stocks with significant coefficient estimates have reduced considerably. Out of 28 positive estimates, only one is found to be significant whereas 145 out of 237 negative estimates are found to be significant. As the coefficients with positive signs are very less in number, they indicate that the information content in implied price is not useful after a day. These results provide strong evidence of information based trading and negligible 
effect of non-synchronous trading in explaining the deviation of observed spot market prices from implied prices.

$* * *$ Insert Table 2 around here $* * *$

\section{Portfolio Approach}

Table 3 presents the results related to average portfolio returns for each of the five portfolios based on ex-post and ex-ante trading rules. We expect that given the positive relationship between risk and return, if pricing error is a measure of risk premium then firms with lowest/highest pricing error should earn lowest/highest returns. We observe a clear pattern between pricing error and portfolio returns. We find the portfolio returns in both tests increasing with the rank of the portfolio. The t-statistics also show that the mean portfolio returns are statistically significant at $1 \%$ level for ex-post test however, they are not found to be significantly different from zero in ex-ante test. The results are consistent with Manaster and Rendleman (1982) and suggest that implied prices contain information about price movement only on the next day. Yesterday's implied price doesn't possess information about tomorrow's returns.

***insert Table 3 around here***

We further conduct the non-parametric chi-square test to examine if the portfolio formation based on ranking of pricing error is different from random portfolios. The test is conducted on the 5 by 5 matrix of return ranks of portfolios. Table 4 presents the frequency distribution and chi-square test statistics of both ex-ante and ex-post tests. The results of chi-square test is encouraging for both ex-post and ex-ante tests. The value of $\chi^{2}(16)$ is found to be high and statistically significant at $1 \%$ level for both the tests. The observed distribution in ex-post test suggests that returns on the portfolios are largely as expected. The observations are clustering on the diagonal of the matrix, which suggest that portfolios, when ranked based on their returns, show the similar pattern to that based on ranking of $\Delta$ 's. We find that out of 1490 days of study, portfolios 1 and 5 give the minimum and maximum returns on 1456 and 1475 days respectively. The significant chi-square statistic also validates that the probability of observed value in the matrix realized purely on chance is nearly zero. The values in return rank matrix for ex-ante test is more evenly spread compared to that of ex-post test however, the observations on the extremes of the diagonal still found to be bunching up. Moreover, the chi-square statistic 
remains significant in ex-ante test suggesting some information value despite the portfolio returns being insignificant (refer Table 3).

$* * *$ insert Table 4 around here $* * *$

One possible reason for chi-square statistic remaining significant despite t-statistic indicating insignificant portfolio returns and failing to reject the hypothesis of no information in ex-post test, is the insensitivity of chi-square statistic towards dispersion in portfolio returns. For example, a very low return earned by a higher ranked portfolio on some days would increase the return variance of that portfolio and also would result in the mean portfolio returns moving towards zero. This two-fold effect may cause the t statistic to be very low and insignificant. Our chi-square test results signify the possible informational role of implied prices in determining future stock prices.

The results of examining the behaviour of $\Delta s$ and the portfolio returns after controlling for liquidity and size is presented in Table 5 and Table 6 respectively. Table 5 reports the mean absolute pricing errors for each quintile formed on the ranking of $\Delta \mathrm{s}$. The ranking here is done after classifying the sample stocks in High, Medium and Low groups based on Amihud liquidity, turnover and firm size each. Here 0/4 portfolio/s is/are the portfolio/s of least/highest liquid stocks based on turnover and reverse is true for Amihud liquidity. We observe that higher liquid stocks have higher mean pricing error and it increases with the increase in the rank of portfolios. It is consistent with our argument that informed traders' trade in liquid stocks and drive the prices away from equilibrium. As a result, the pricing error of high liquid stocks exceeds significantly than that of low liquid stocks. We find converse results for firm size where the mean pricing errors are increasing with increase in size of the firm. It provides evidence of informed trading in large size firms.

***insert Table 5 around here***

Table 6 presents the portfolio returns after controlling for liquidity and size. We observe consistent pattern of portfolio returns increasing with rank of the portfolios only for highly liquid group for both measures of liquidity i.e. Amihud liquidity and turnover. The pattern of Amihud measure is opposite because portfolio 4 is the least liquid portfolio as per Amihud measure of illiquidity. However, the returns of extreme portfolios are significantly different 
only for Amihud liquidity. We do not find a consistent pattern for the medium and low levels of liquidity and for the firm size. It reveals that informed trading takes place mostly in high liquid stocks.

$$
\text { ***insert Table } 6 \text { around here*** }
$$

Next, we present the results of our examination of whether the $\Delta$ 's provide additional information beyond that is given by Carhart (1997) four factors regarding future portfolio returns. We run regression Equation (6) for all five portfolios separately and report the results thereof in Table 7. We expect that for pricing error to be a priced risk factor, the alpha in the regression model should be significant. We find the alpha to be significant in explaining the daily portfolio returns for all the five portfolios in case of ex-post test which suggests that the pricing error is due to the additional compensation demanded by investors for taking risks other than those covered by Carhart four factors. Consistent with literature, the coefficients of excess MKT factor is positive, significant and values close to one across portfolios. The SMB factor has positive and significant effect for lower ranked portfolios and negative effect for portfolios 3 and above. It indicates that size premium positively affects the stocks with smaller mispricing and vice versa however, the negative effects are not significant. HML factor has positive and significant relationship with returns on lower rank portfolio, which is similar to SMB effects and implies that marginally mispriced stocks load more on size and value factors compared to stock with considerable mispricing. WML has negative and significant relationship with portfolio returns across portfolios, which is consistent with literature. We observe high $\mathrm{R}^{2}$ in the regressions of all portfolios with the highest value of $71.5 \%$ for portfolio 1 .

We also test if riskless profit making is possible by following the long-short portfolio investment strategy where an investor goes short in lowest $\Delta$ portfolio and long in highest $\Delta$ portfolio. We estimate Equation (7) to examine if the strategy is profitable and report the results in the column L/S strategy of Table 7. We expect a significant and positive alpha coefficient in the $\mathrm{L} / \mathrm{S}$ regression for the fact that portfolio with higher ranks earn higher returns if $\Delta$ is informative. We observe that the alpha coefficient is positive and significant at $1 \%$ level of significance and suggest that a daily riskless return of $0.05 \%$ is possible using long short strategy based on pricing error signal. The loadings of market, size, value and momentum premium factors are negative in the regression however, the value factor loading is found to be statistically insignificant. This indicates that firms with low pricing error load heavily on 
market portfolio and on large size and high performing firms. It is also noteworthy that while the adjusted R-squared drops considerably in long short regression yet, our results indicate that pricing error is due to additional risk premium demand by investors and is a priced risk factor in the time series.

***insert Table 7 around here***

\section{Conclusions}

The study shows that the implied stock prices computed using closing futures market prices possess information regarding equilibrium stock prices above and over the information already contained in closing spot market prices of stocks. A twofold explanation of information content is possible. First, as the transactions in the two markets do not always take place at the same time and so additional information can merely be the more recent information. However, the closing futures price revealing the best estimate of equilibrium stock price is possible due to preference of trading futures contracts by traders having private information about firms.

We separate the information effect from the effect of non-synchronous observations and then test whether the information in implied price helps investors to enhance their portfolio returns by buying the portfolio at the closing price on the day the implied prices are calculated and selling on the next day. Our results show that it is possible to earn excess returns within a span of 24 hours based on information contained in implied prices. Even with the lapse of 24 hours time the portfolio returns ranked largely as predicted however, it didn't show that the mean returns of the portfolios were significant. Our analysis of pricing error series and portfolio returns after controlling for liquidity and firm size also reveals that informed trading takes place in high liquid stocks in Indian SSFs market. Moreover, our results indicate that pricing error is the result of additional risk premium demanded for those equity investments related risks that are not captured by popular Carhart factors. The long-short portfolio investment strategy results indicate that making riskless profit based on signal of price discrepancy in stock and stock futures market is quite a possibility in India. We conclude that the closing futures prices of single stock futures are informative about next day equilibrium stock prices and it provides significant profitable opportunities for traders.

\section{References}


Agarwalla, S. K., Jacob, J., \& Varma, J. R. (2013). Four factor model in Indian equities market, Working Paper W.P. No. 2013-09-05, Indian Institute of Management, Ahmedabad.

Amihud, Y. (2002). Illiquidity and stock returns: cross-section and time-series effects. Journal of financial markets, 5(1), 31-56.

Aslan, H., Easley, D., Hvidkjaer, S., \& O'Hara, M. (2011). The characteristics of informed trading: Implications for asset pricing. Journal of Empirical Finance,18(5), 782-801.

Bialkowski, J., \& Jakubowski, J. (2012). Determinants of Trading Activity on the Single-Stock Futures Market: Evidence from the Eurex Exchange, The Journal of Derivatives, 19(03), 29-47.

Brailsford, T. J., \& Cusack, A. J. (1997). A comparison of futures pricing models in a new market: The case of individual share futures. Journal of Futures Markets, 17(5), 515541.

Carhart, M. M. (1997). On persistence in mutual fund performance. The Journal of finance, 52(1), 57-82.

Chakravarty, S., Gulen, H., \& Mayhew, S. (2004). Informed trading in stock and option markets. The Journal of Finance, 59(3), 1235-1258.

Chan, K., Chung, Y. P., \& Johnson, H. (1993). Why Option Prices Lag Stock Prices: A Trading-based Explanation. The Journal of Finance, 48(5), 1957-1967.

Chen, C. R., Lung, P. P., \& Tay, N. S. (2005). Information flow between the stock and option markets: Where do informed traders trade?. Review of Financial Economics, 14(1), 123.

Cummings, J. R., \& Frino, A. (2011). Index arbitrage and the pricing relationship between Australian stock index futures and their underlying shares. Accounting \& Finance, 51(3), 661-683. 
Fama, E. F., \& French, K. R. (1992). The cross-section of expected stock returns. the Journal of Finance, 47(2), 427-465.

Hemler, M. L., \& Longstaff, F. A. (1991). General equilibrium stock index futures prices: Theory and empirical evidence. Journal of Financial and Quantitative Analysis, 26(03), 287-308.

Kiymaz, H., \& Berument, H. (2003). The day of the week effect on stock market volatility and volume: International evidence. Review of Financial Economics,12(4), 363-380.

Kumar, U., \& Tse, Y. (2009). Single-stock futures: Evidence from the Indian securities market. Global Finance Journal, 20(3), 220-234.

Manaster, S., \& Rendleman, R. J. (1982). Option prices as predictors of equilibrium stock prices. The Journal of Finance, 37(4), 1043-1057.

Ni, S. X., Pan, J., \& Poteshman, A. M. (2008). Volatility information trading in the option market. The Journal of Finance, 63(3), 1059-1091.

Ramaswamy, K., \& Sundaresan, S. M. (1985). The valuation of options on futures contracts. The Journal of Finance, 40(5), 1319-1340.

Rogalski, R. J. (1984). New Findings Regarding Day-of-the-Week Returns over Trading and Non-Trading Periods: A Note. The Journal of Finance, 39(5), 1603-1614.

Sarwar, G. (2005). The informational role of option trading volume in equity index options markets. Review of Quantitative Finance and Accounting, 24(2), 159-176.

Shastri, K., Thirumalai, R. S., \& Zutter, C. J. (2008). Information revelation in the futures market: Evidence from single stock futures. Journal of Futures Markets, 28(4), 335353.

Theissen, E. (2012). Price discovery in spot and futures markets: A reconsideration. The European Journal of Finance, 18(10), 969-987. 
Turkington, J., \& Walsh, D. (2000). Informed traders and their market preference: Empirical evidence from prices and volumes of options and stock.Pacific-Basin Finance Journal, 8(5), 559-585.

Vipul, (2005). Temporal Variation in Futures Mispricing. VIKALPA, 30(4), 25.

Vipul, (2008), Mispricing, Volume, Voltaility and Open Interest : Evidence from Indian Future Market, Journal of Emerging Market Finance, 7(3), 263-292.

Wang, J. (2011). Price behavior of stock index futures: Evidence from the FTSE Xinhua China A50 and h-share index futures markets. Emerging Markets Finance and Trade, 47, 6177.

Table 1: Time Series Behaviour of Average Pricing Error Seriesa

\begin{tabular}{lll}
\hline Variable & Parameter t-values \\
& Estimates & \\
\hline
\end{tabular}




\section{Panel A}

Day of the Week Effect

$\begin{array}{lll}\text { Intercept }(\alpha) & -0.0081^{* * *} & -8.14 \\ \text { Monday } & -0.044^{* *} & -2.26 \\ \text { Tuesday } & 0.000 & 0.36 \\ \text { Wednesday } & 0.002 & 1.69 \\ \text { Thursday } & 0.001 & 0.88\end{array}$

$\mathrm{R}^{2}: 0.580 \%$, F-Stats: $2.15^{*}$

\section{Panel B}

\section{Month of The Year Effect}

$\begin{array}{lll}\text { Intercept }(\gamma) & -0.003^{* *} & -2.18 \\ \text { January } & -0.005^{* *} & -2.19 \\ \text { February } & -0.004^{* *} & -2.03 \\ \text { March } & -0.002 & -0.88 \\ \text { April } & 0.000 & 0.17 \\ \text { May } & -0.004 & -1.79 \\ \text { June } & -0.005^{* *} & -2.54 \\ \text { July } & -0.003 & -1.28 \\ \text { August } & -0.004^{* *} & -2.01 \\ \text { September } & -0.001 & -0.60 \\ \text { October } & -0.006^{* *} & -2.42 \\ \text { November } & -0.003 & -1.58\end{array}$

$\mathrm{R}^{2}: 1.19 \%$, F-Stats: $1.62 *$

Here $* * * p<.001, * * p<.05, * p<.10$

a: Table 1 shows the results of seasonality examination in time series of cross sectional average of pricing errors.

Day of the week and months of the year regression results with the coefficients of days and months are presented in Panel A and B respectively. The coefficients of respective days and months are reported and their significance levels are indicated through asterisk. The corresponding $t$-values and p-values are shown in separate columns. Regression $R^{2}$ and related F-Stats are also indicated for both regressions.

Table 2: Stock Returns and Pricing Errors Regression b

Regression Model: $\mathrm{R}_{\mathrm{i}, \mathrm{t}}=\theta_{\mathrm{i}}+\delta_{\mathrm{i} .} \mathrm{R}_{\mathrm{m}, \mathrm{t}}+\pi_{\mathrm{i}} . \Delta_{\mathrm{i}, \mathrm{t}}+\psi_{\mathrm{i}} . \Delta_{\mathrm{i}, \mathrm{t}-1}+\varepsilon_{\mathrm{i}, \mathrm{t}}$ 


\section{Pricing Error Coefficient}

Regression with $+\mathrm{Ve} \pi_{\mathrm{j}}$

Regression with - Ve $\pi_{j}$

003

001

$$
\text { Total }
$$

Pricing Error Lag Coefficient

Regression with + Ve $\psi_{\mathrm{j}}$

028

001

Regression with $-\mathrm{Ve} \psi_{\mathrm{j}}$

\section{Total}

265

146

b: Table 2 shows the regression results, which investigate the effect of non-synchronous trading on pricing error. The stock counts for positive and negative parameter estimates of pricing error and lag pricing error are shown with the count of significant estimates for entire sample of 265 stocks. 


$\begin{array}{llllll}\text { Mean Returns (\%) } & -0.026 & -0.011 & -0.001 & 0.008 & 0.031 \\ \begin{array}{l}\text { (t-statistics) } \\ \text { Ex-ante Rules }\end{array} & (-29.45)^{* * *} & (-17.16)^{* * *} & (-2.87)^{* * *} & (13.59)^{* * *} & (34.05)^{* * *} \\ \text { Mean Returns } & -0.000 & 0.000 & 0.000 & 0.000 & 0.000 \\ \text { (t-statistics) } & (-0.23) & (1.03) & (0.73) & (0.65) & (0.22) \\ & * * * \mathrm{p}<.001 & & & & \end{array}$

d: Table 3 presents the result of average portfolio returns for portfolios 1 to 5. The mean portfolio returns along with their corresponding $t$ statistics are shown in parentheses and asterisks indicate significance levels. Results are presented for both ex-post and ex-ante trading rules. 


\section{Table 4}

\section{Test on Frequency Distribution of Portfolios}

\section{Based on Return Rankse}

\begin{tabular}{ccccccc}
\multicolumn{7}{c}{ Ex-Post Results* } \\
Portfolios & 1 & 2 & 3 & 4 & 5 & Total \\
0 & 1456 & 21 & 4 & 3 & 6 & 1490 \\
1 & 21 & 1451 & 11 & 6 & 1 & 1490 \\
2 & 6 & 12 & 1458 & 10 & 4 & 1490 \\
3 & 4 & 6 & 16 & 1460 & 4 & 1490 \\
4 & 3 & 0 & 1 & 11 & 1475 & 1490
\end{tabular}

* The no-information hypothesis upholds that the frequency in each of the cells above should be equal to $1490 / 5$ or 298 .

Chi-square test statistic: $\chi^{2}(16)=28332.24 * * *$

\begin{tabular}{ccccccc}
\hline \multicolumn{7}{c}{ Ex-Ante Results ${ }^{\wedge}$} \\
Portfolios & 1 & 2 & 3 & 4 & 5 & Total \\
0 & 505 & 284 & 243 & 233 & 224 & 1489 \\
1 & 204 & 319 & 366 & 356 & 244 & 1489 \\
2 & 229 & 293 & 389 & 308 & 270 & 1489 \\
3 & 246 & 324 & 290 & 351 & 278 & 1489 \\
4 & 305 & 269 & 201 & 241 & 473 & 1489 \\
& & & & & & \\
\hline
\end{tabular}

${ }^{\wedge}$ The no information hypothesis uphold that the frequency in each of the cells above should be equal to $1489 / 5$ or 297.80

Chi-square test statistic: $\chi^{2}(16)=275.26 * * *$

$* * * \mathrm{p}<.001$

e: Table 4 presents the frequency distribution of portfolios based on ranking of pricing errors and returns for both ex-post and ex-ante trading rules. The chi-square test statistics are also shown along with their significance indicated by asterisks. 
Table 5: Behaviour of Absolute Average Pricing Errorsf

\begin{tabular}{lrrrr}
\hline Portfolios & Turnovr & Amihud_liquidity & Size \\
\hline & 0 & $0.189 \%$ & $0.476 \%$ & $0.161 \%$ \\
1 & $0.172 \%$ & $0.304 \%$ & $0.181 \%$ \\
& 2 & $0.278 \%$ & $0.221 \%$ & $0.261 \%$ \\
& 3 & $0.335 \%$ & $0.169 \%$ & $0.426 \%$ \\
& 4 & $0.420 \%$ & $0.219 \%$ & $0.212 \%$ \\
\hline Diff (4-0) & & $0.230 \%$ & $-0.256 \%$ & $0.050 \%$ \\
\hline T-value & & 10.27 & -6.78 & 4.58
\end{tabular}

f: Table 5 presents the averages of absolute pricing error for portfolios $0,1,2 \ldots ., 4$. The portfolios are formed on daily basis and average pricing error for a portfolio is computed by averaging the daily average pricing error of the portfolio across days of study. Stocks are ranked daily based on daily turnover (measured by total no. of shares traded/total outstanding shares), amihud liquidity estimate, and firm size (measured by log of daily market cap). Lowest ranked stocks go to portfolio 0 and highest ranked stocks form part of portfolio 4 for all three classifications i.e. turnover, amihud_liquidity and size. Portfolio 0 in case of turnover is portfolio of least liquid stocks whereas for amihud_liquidity it indicates the portfolio of highest liquid stocks. Portfolio 0 for size is portfolio of stocks with least market capitalization indicating smallest firms and vice-versa for portfolio 4. 


\section{Table 6: Firm Characteristics and Portfolio Returnsg}

\begin{tabular}{l|lll|lll|lll}
\hline Portfolios & \multicolumn{3}{|c|}{ Amihud } & \multicolumn{3}{c|}{ Turnover } & \multicolumn{3}{c}{ Size } \\
& High & Medium & Low & High & Medium & Low & High & Medium & Low \\
$\mathbf{0}$ & 0.0023 & -0.0008 & -0.0001 & 0.0022 & 0.0002 & -0.0018 & 0.0003 & 0.0009 & -0.0005 \\
$\mathbf{1}$ & 0.0020 & -0.0013 & 0.0010 & 0.0026 & -0.0021 & -0.0024 & -0.0001 & -0.0007 & -0.0007 \\
$\mathbf{2}$ & 0.0019 & 0.0007 & -0.0005 & 0.0026 & -0.0038 & -0.0056 & -0.0029 & -0.0029 & -0.0004 \\
$\mathbf{3}$ & 0.0019 & -0.0007 & 0.0002 & 0.0034 & -0.0032 & -0.0047 & -0.0033 & -0.0010 & -0.0003 \\
$\mathbf{4}$ & 0.0010 & -0.0001 & 0.0000 & 0.0039 & 0.0004 & -0.0019 & 0.0007 & 0.0011 & -0.0008 \\
\hline Diff (4-0) & 0.0033 & 0.0007 & 0.0001 & 0.0017 & 0.0002 & -0.0001 & 0.0004 & 0.0002 & -0.0003 \\
\hline t-value & 2.32 & 0.54 & 0.11 & 0.08 & 0.19 & -0.76 & 0.2 & 0.11 & -0.23 \\
\hline \hline
\end{tabular}

g: Table 6 presents the portfolio returns (in \%) based on pricing error after classifying sample stocks based on firm characteristics i.e. firm liquidity and firm size. The liquidity is measured alternatively by Amihud measure (absolute stock returns/daily dollar volume) and by turnover (no. of stocks traded/total outstanding stocks). Firm size is measured by logarithm of daily market capitalization of stocks). The sample stocks are divided in three groups based on the liquidity and size criteria i.e. High, Medium and Low. Quintiles are formed within each group based on pricing error and average portfolio returns are computed subsequently for each quintiles. The difference of extreme portfolios is computed and related t-statistics are shown.

Table 7: Time Series Relation between Pricing Error and Portfolio returns (Ex-Post) ${ }^{13}$ e

\footnotetext{
${ }^{13}$ We also estimate the analysis for ex-ante portfolio returns. Similar to previous results reported in Table 4 the parameter estimates are highly insignificant in almost all cases. We avoid reporting those results to conserve space.
} 


\begin{tabular}{lcccccc}
\hline Variables & Portfolio & Portfolio & Portfolio & Portfolio & Portfolio & L/S \\
& $\mathbf{0}$ & $\mathbf{1}$ & $\mathbf{2}$ & $\mathbf{3}$ & $\mathbf{4}$ & Strategy \\
\hline Alpha (\%) & $-0.024 * * *$ & $-0.010^{* * *}$ & $-0.001 * * *$ & $0.008^{* * *}$ & $0.030^{* * *}$ & $0.055^{* * *}$ \\
& $(-55.57)$ & $(-36.01)$ & $(-4.28)$ & $(17.41)$ & $(47.75)$ & $(64.39)$ \\
Excess_MKTRT & $1.353^{* * *}$ & $1.145^{* * *}$ & $1.058^{* * *}$ & $1.022^{* * *}$ & $1.159 * * *$ & $-0.194 * * *$ \\
(MKT) & $(40.70)$ & $(54.00)$ & $(43.68)$ & $(29.86)$ & $(24.49)$ & $(-3.05)$ \\
Size_Premium & $0.276^{* * *}$ & $0.075^{* *}$ & -0.032 & -0.064 & -0.087 & $-0.354^{* * *}$ \\
(SMB) & $(3.53)$ & $(1.99)$ & $(-0.75)$ & $(-1.05)$ & $(-1.03)$ & $(-3.11)$ \\
Value_Premium & $0.257 * * *$ & $0.145^{* * *}$ & $0.119 * * *$ & $0.097 *$ & 0.106 & -0.15 \\
(HML) & $(4.49)$ & $(3.98)$ & $(2.87)$ & $(1.66)$ & $(1.31)$ & $(-1.37)$ \\
Momentum_prem. & $-0.115 * *$ & $-0.077 * *$ & $-0.109 * * *$ & $-0.162 * * *$ & $-0.348 * * *$ & $-0.233 * *$ \\
(WML) & $(-2.21)$ & $(-2.33)$ & $(-2.87)$ & $(-3.02)$ & $(-4.69)$ & $(-2.33)$ \\
Adj. R ${ }^{2}:$ & 0.581 & 0.715 & 0.631 & 0.45 & 0.364 & 0.015 \\
F-Statistic: & $517.77 * * *$ & $935.95 * * *$ & $639.60^{* * *}$ & $305.99 * * *$ & $214.67 * * *$ & $6.67 * * *$ \\
Observations: & 1490 & 1490 & 1490 & 1490 & 1490 & 1490 \\
\hline \hline
\end{tabular}

$e^{e}:$ In the above Table 7 MKT, SMB, HML and WML are factors of Carhart (1997) model representing excess market returns, size premium (small minus big), value premium (high minus low) and momentum premium (winners minus losers) respectively. The coefficients are reported with their respective t-values in parentheses for all five portfolios and for $L / S$ (long /short) strategy. The adjusted $R$-squared and $F$ statistic of analysis of variance (ANNOVA) are also reported. Statistical significance of the coefficients is indicated in the following manner: *** $p<.001, * * p<.05$ and $* p<.10$.

Figure 1: Product wise share of derivatives on NSE*

(As percentage of total turnover) 


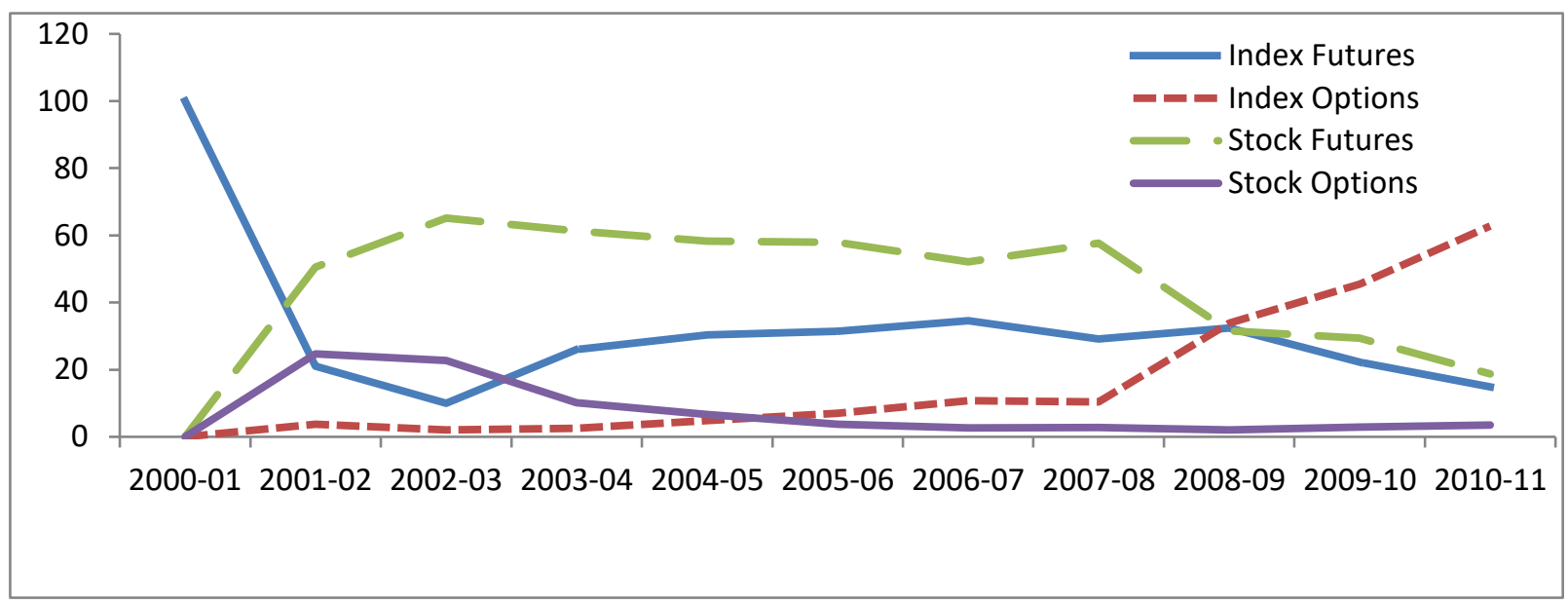

* Figure 1 shows the product-wise turnover of equity derivatives traded on NSE, India since its inception in 2001 and indicates the highest trading for Single Stock Futures.

Source: Data compiled by authors from www.nseindia.com 